\title{
Breast cancer mortality in Mexico. An age-period-cohort analysis
}

\author{
Francisco Franco-Marina MC, MPH, MHSc,, ${ }^{(1)}$ Eduardo Lazcano-Ponce, Dr SP,(2) \\ Lizbeth López-Carrillo QBP, Dr PH. ${ }^{(2)}$
}

\section{Franco-Marina F, Lazcano-Ponce E, López-Carrillo L. Breast cancer mortality in Mexico. An age-period-cohort analysis. Salud Publica Mex 2009;5 I suppl 2:SI57-SI64.}

\begin{abstract}
Objective. To assess the age, period and cohort effects on breast cancer (BC) mortality in Mexico. Material and Methods. Age, period and cohort curvature trends for BC mortality were estimated through the Poisson Regression model proposed by Holford. Results. Nationally, BC death rates have leveled off since 1995 in most age groups. BC mortality trends are mainly determined by birth cohort and age effects in Mexico.Women born between 1940 and 1955 show the highest rate of increase in $\mathrm{BC}$ mortality. Women born afterwards still show an increasing trend but at a much lower rate. Mammography and adjuvant therapy have had a limited impact on mortality. Potential reasons for observed patterns are discussed.An increase in BC mortality in Mexico is expected in the following decades. Conclusions. Mammography screening programs and timely access to effective treatment should be a national priority to reverse the expected increasing $\mathrm{BC}$ mortality trend.
\end{abstract}

Keywords: breast cancer mortality, age-period-cohort analysis, Mexico
Franco-Marina F, Lazcano-Ponce E, López-Carrillo L. Mortalidad por cáncer de mama en México.

Un análisis de edad-periodo-cohorte.

Salud Publica Mex 2009;5 I supl 2:SI 57-SI64.

\section{Resumen}

Objetivo. Evaluar efectos de edad-periodo-cohorte en la mortalidad por cáncer de mama (CaMa) en México. Material y métodos. Las tendencias de los efectos de edad-periodocohorte fueron estimados mediante un modelo de regresión de Poisson propuesto por Holford. Resultados. Las tasas de mortalidad por CaMa se han estabilizado en la mayoría de los grupos de edad desde 1995 y están determinadas principalmente por efectos de cohorte y edad. Las mujeres nacidas entre 1940 y 1955 muestran los mayores aumentos en la mortalidad en comparación con las nacidas después de este período. La mamografía y la terapia adyuvante han tenido un impacto limitado sobre la mortalidad. Se discuten posibles explicaciones de las tendencias observadas. En las siguientes décadas se espera continúe aumentando la mortalidad por $\mathrm{CaMa}$. Conclusiones. El acceso a mamografía y a tratamiento oportuno y efectivo debieran ser una prioridad para revertir la tendencia creciente esperada de la mortalidad por CM.

Palabras claves: mortalidad por cáncer de mama, análisis edad-periodo-cohorte, México

(I) División de Epidemiología. Instituto Nacional de Rehabilitación. México.

(2) Instituto Nacional de Salud Pública. México.

Received on: November 27,2008 • Accepted on: December 17, 2008

Address reprint requests to: Francisco Franco-Marina. Instituto Nacional de Rehabilitación. División de Epidemiología. Calz. México-Xochimilco 289 Col.Arenal de Guadalupe,Tlalpan, I4389 México, DF.

E-mail: franciscofrancomarina@gmail.com 
$\mathrm{B}^{\mathrm{r}}$ reast cancer became the leading cause of female cancer deaths after cervical cancer in 2005, with a steadily increasing trend in Mexico. ${ }^{1}$ Breast cancer death rates vary by a factor of four between the highest and lowest rates in the world and Mexico has a low breast cancer death rate on a worldwide scale. ${ }^{2}$ However, breast cancer mortality is increasing more rapidly in countries in Latin America and Asia which have the lowest incidence rates ( 7 to $14 / 100000$ ) compared to those with the highest rates (17 to $27 / 100000){ }^{3}{ }^{3}$

The interpretation of breast cancer mortality trends is complicated because they might be the combined result of changes in risk factors and screening practices as well as better survival due to treatment improvements. One way of disentangling these effects consists in attempting to separate age, period and cohort effects implied in the trends through an appropriate statistical model. In such analysis, period effects may capture mainly the effects on breast cancer death rates of factors related to improved survival such as screening and adjuvant therapy, whereas cohort effects may give some clues of risk factors changing the incidence of the disease.

The aim of this paper is to characterize the age, period and cohort effects of breast cancer mortality in Mexico and to better explain the role of advances in early detection and treatment and changes in reproductive and other breast cancer risk factors that may have taken in place in the country over the past three decades.

\section{Materials and Methods}

\section{Mortality data}

Individual $\mathrm{BC}$ deaths occurring in women between 1980 and 2005 were obtained from the official mortality databases generated by Mexico's National Institute of Geography and Statistics (INEGI, per its abbreviation in Spanish). The basic cause of death was coded in these databases using the ninth revision of the International Classification of Diseases (ICD-9) between 1980 and 1997 and the tenth revision afterwards (ICD-10). According to a WHO ICD translator, ${ }^{4}$ ICD-9 breast cancer codes (174.0-174.9) map only to ICD-10 breast cancer codes (C50.0-C50.9) and vice versa.

Official mid-year female population estimates at the state level were obtained from the Mexico's National Population Council (CONAPO, per its abbreviation in Spanish) for 1980 through $2005 .{ }^{5}$ Population estimates were available in five-year age groups throughout the analyzed period and in single-year of age for 2005. Some of the statistical analyses presented in this study required population estimates by single-year of age. Thus, for 1980 through 2004 we generated such estimates by applying the single-year of age proportions within each five-year age group observed in 2005 to the fiveyear age groups population estimates observed in each year between 1980 and 2004 .

\section{Statistical analysis}

All statistical analyses were confined to women aged 25 and older. Age adjusted death rates were calculated through the direct method ${ }^{6}$ using, in all instances, the national population estimates for 2005 broken down by five-year age groups.

Trends in the absolute number of breast cancer deaths or the corresponding death rates were modeled through joinpoint Poisson regression using the Joinpoint Regression Program. ${ }^{7}$ Joint point regression is a nonlinear statistical technique aimed at identifying changes in trends in the response variable over the analyzed period (i.e. deaths or death rates). ${ }^{8}$ Unknown points in time at which the response changes in trend (joinpoints) are identified by the grid search method. Models with a variable number of joinpoints ( 0 through 4 ) are then compared through permutation tests with $p$-values found by Monte Carlo methods and a Bonferroni correction to maintain an overall asymptotic significance level. The final model consists of a series of lines with different slopes connected together at the joinpoints.

Age (a), period (p) and cohort (c) curvature trends for breast cancer mortality $(\lambda)$ were estimated through the following Poisson Regression Age-Period-Cohort (APC) model, proposed by Holford: ${ }^{9}$

$$
\log _{(a, p, c)}=\mu+[\beta a+\beta p] a^{\prime}+[\beta p+\beta c] c^{\prime}+\alpha(a)+\pi(p)+\gamma(c)
$$

where $a^{\prime}$ and $c^{\prime}$ are the curvature components of the age and cohort effects, $[\beta p+\beta c]$ is called the "net drift parameter" indicating the overall direction in which the mortality trend is moving, and $\alpha, \pi$ and $\gamma$ are the parameters describing the age, period and curvature trends. The net drift parameter was extracted using Holford's naive average. The model was fitted so that age effects are presented as death rates for the reference cohort. Additionally, cohort effects represent death rate ratios relative to the reference cohort, whereas period effects are constrained to be 0 on average with 0 slope.

The APC model just described was fitted using national information on deaths and population between 1980 and 2005 for women aged 25 through 85 years and born between 1905 and 1975. The model was fit on a tabulation of deaths and populations using single-years of age and period to avoid overlapping cohorts and to give more detail to the trends. Natural splines with seven parameters for the age, period and cohort terms 
were incorporated in the APC modeling to reduce random variation due to the use of such detailed tabulation. The same APC model was also fit for four Mexican state clusters, created from an analysis published by Tuiran et al. for the calendar year in which each state reached an overall fertility rate of three children or less..$^{10}$ Using the results from these models, directly age-adjusted death rates were calculated for the analyzed birth cohorts using the 2005 national population as standard.

All APC modeling was performed using the implementation provided by Carstensen ${ }^{11}$ in the R Statistical Package. ${ }^{12}$

\section{Results}

Between 1980 and 2005, a total of 67854 breast cancer deaths were observed in Mexican women. Only 172 $(0.25 \%)$ of those occurred in women younger than 25 years of age and $199(0.25 \%)$ had an unknown age. Over the analyzed period, the mean age at death from breast cancer remained very close to an average of 57.3 years (standard deviation $=0.38$ ). In addition, the population age distribution for Mexican women aged 25 and older over the analyzed period has also remained close to an average age of 44.7 years (standard deviation $=0.24$ ).

Figure 1 plots the annual number of breast cancer deaths in Mexican women aged 25 and older as well as their fitted trends. Three trend periods with slopes

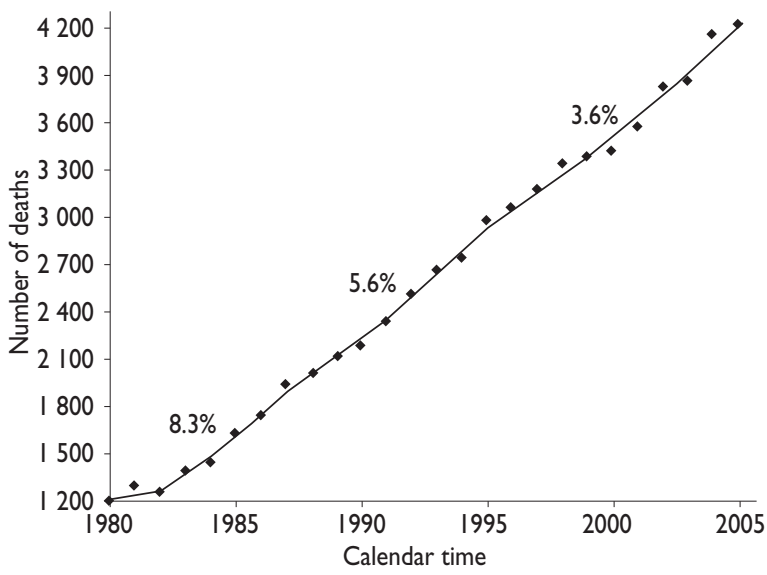

Figure I. Annual breast cancer deaths in Mexican WOMEN AGED 25 YEARS AND OLDER. DOTS REPRESENT THE OBSERVED NUMBER OF BREAST CANCER DEATHS. LINES WERE OBTAINED USING JOINPOINT POISSON REGRESSION ON DEATH COUNTS. ContINUOUS LINES ARE LINE SEGMENTS WITH YEAR SLOPES SIGNIFICANTLY DIFFERENT FROM ZERO. ANNUAL PERCENT CHANGE IS PROVIDED FOR SIGNIFICANT LINE SEGMENTS significantly different from zero are identified. Between 1982 and 1987 the absolute number of breast cancer deaths in Mexican women aged 25 and older grew 8.3\% annually. After this period, breast cancer deaths have increased at increasingly lower rates $(5.6 \%$ between 1987 and 1995 and 3.6\% between 1995 and 2005).

Age-specific breast cancer death rate trends for five age groups are shown in figure 2. A clear gradient of higher breast cancer death rates with increasing age is observed throughout the analyzed period. The four younger age groups comprising Mexican women between 25 and 74 years of age show very similar trends between 1980 and 2005. In these age groups death rates increased annually between 2.6 and 3.5\% during the first 13 to 15 years of the analyzed period, but afterwards death rates show annual increases not statistically significant from zero. On the other hand, Mexican women aged 75 years and older show an annual death rate increase of 4.9\% between 1980 and 1987 and a 1.2\% increase between 1987 and 2005.

Figure 3 graphically presents the estimated age, period and cohort female breast cancer mortality effects. Death rates by age for the 1940-1941 birth cohorts are plotted on a logarithmic scale. Breast cancer death rates increase very fast between 25 and 35 years of age and continue to increase with increasing age, albeit at lower rates. The fitted APC model implies that this age effect is constant among birth cohorts and periods. The

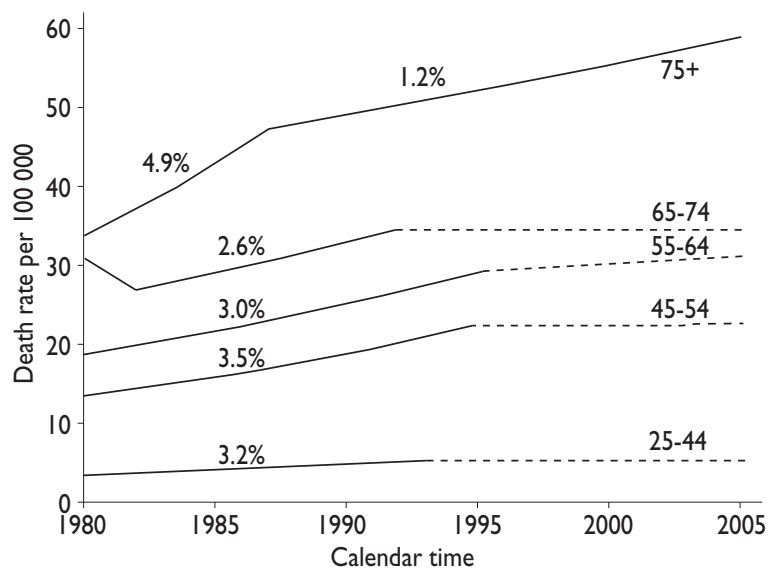

Figure 2. Breast cancer death rate trends in Mexican WOMEN BY AGE GROUP. LINES WERE OBTAINED USING JOinPoint PoIsSON Regression. ContinUous LINES ARE LINE SEGMENTS WITH STATISTICALLY SIGNIFICANT YEAR SLOPES. ANNUAL PERCENT CHANGE IS PROVIDED FOR SIGNIFICANT LINE SEGMENTS 

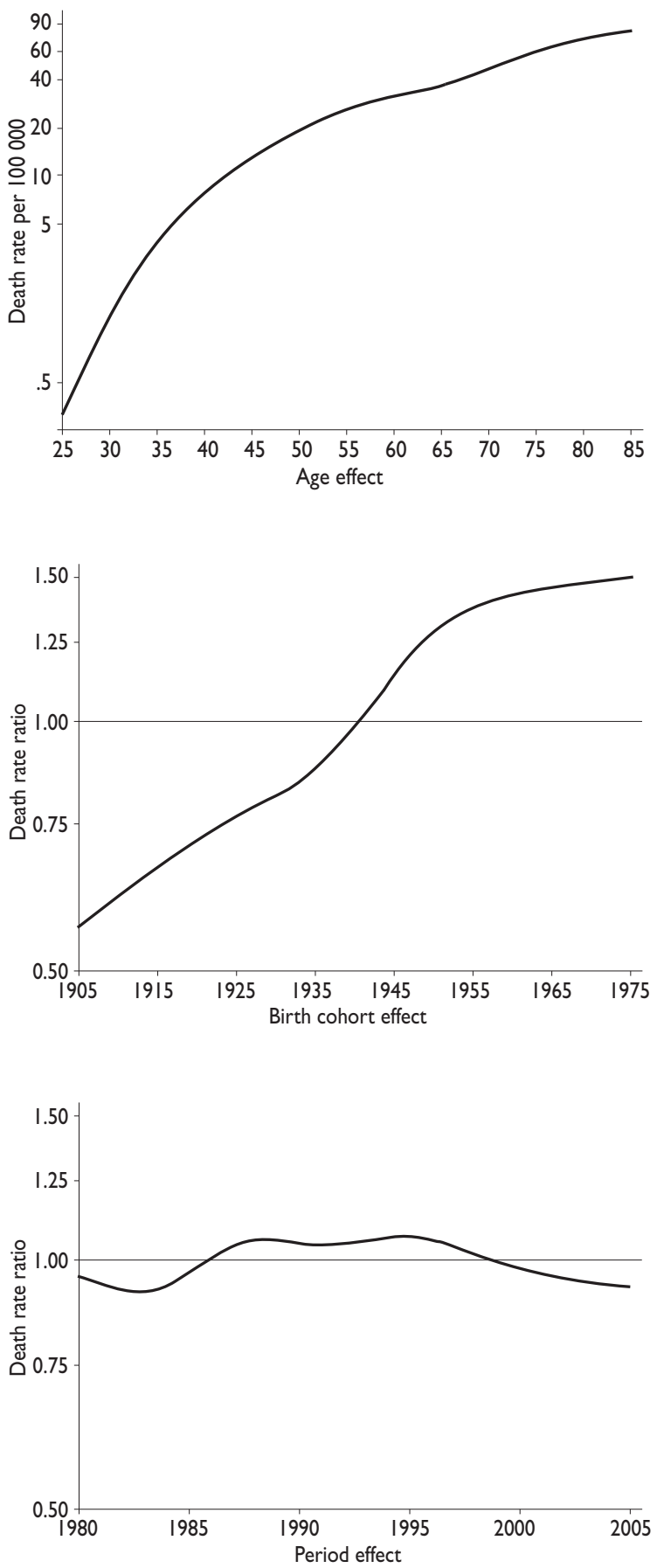

Figure 3. Age, Period AND COHORT efFects for female BREAST CANCER MORTALITY IN MEXICO, USING THE HOLFORd Age-Period-Cohort model.Age effects are death Rates PER I00 000 PERSON-YEARS FOR THE REFERENCE COHORT. COHORT EFFECTS REPRESENT DEATH RATE RATIOS RELATIVE to the reference cohort (1940-194I). Period effects ARE ALSO DEATH RATE RATIOS RELATIVE TO A ZERO SLOPE.THE NET DRIFT PARAMETER WAS ESTIMATED AT I.0I7 birth cohort effect on breast cancer death rates is shown as death rate ratios with respect to the 1940-1941 birth cohorts. It consists of higher breast cancer death rates in the more recent cohorts born after that period (19401941) in contrast to earlier cohorts born at the beginning of the $20^{\text {th }}$ century; the latter are estimated to have almost one-half the breast cancer death rates estimated for the 1940-1941 birth cohorts and almost one-third of those estimated for the 1975 birth cohort. In addition, breast cancer death rates increase more rapidly in women born between 1935 and 1950 and considerably more slowly in women born afterwards. Finally, as it was expected, the estimated period effect, also expressed as death rate ratios, shows a much lower intensity than the age and cohort effects. Nevertheless, breast cancer death rates show a slight increase during the 1980s, a leveling off during the first half of the 1990s and a continuous slight decrease afterwards.

Using information on the year that Mexican states reached a global fertility rate of three children per woman we created four state clusters with a roughly similar population. Table I summarizes fertility and breast cancer mortality patterns for the created clusters. All state clusters had similar fertility patterns in 1965, but global fertility rates in states belonging to cluster $\mathrm{A}$ had a faster decline in fertility than those observed in the other state clusters, especially cluster D. Additionally, states in cluster A also showed the lowest marginality index and those in cluster D, the highest. Cluster states B and $C$ showed an intermediate average marginality and also higher variability in marginality than regions $A$ and D. Between 1980 and 2005, all state clusters showed a non-linear adjusted death trend with a progressively decreasing slope. Annual percent changes in age-adjusted death rates during the most recent analyzed decade (1996 to 2005) differ between state clusters. Cluster B shows a significant rising trend, whereas the rest of the clusters show no significant trend. Nevertheless, cluster A may possibly have a slight decrease in breast cancer mortality and clusters $\mathrm{C}$ and $\mathrm{D}$ a slight increase during the last analyzed decade.

Figure 4 plots the age-adjusted breast cancer death rates for birth cohorts for women aged 25 and older derived from fitting the Holford Age-Period-Cohort model in each of the state clusters. These rates can be compared to the observed breast cancer death rate in Mexico in 2005 of 15.5 per 100000 women for this age group. In all cohorts, breast cancer death rates are higher in cluster states with faster fertility declines. Also, the most recently born cohorts show less variability in breast cancer death rates among state clusters. Additionally, the rising trend of breast mortality in the most recently born cohorts is seen in all state clusters but it is more 
Table I

Fertility AND breast CANCER mortality patterns of ANalyzed MeXican state Clusters

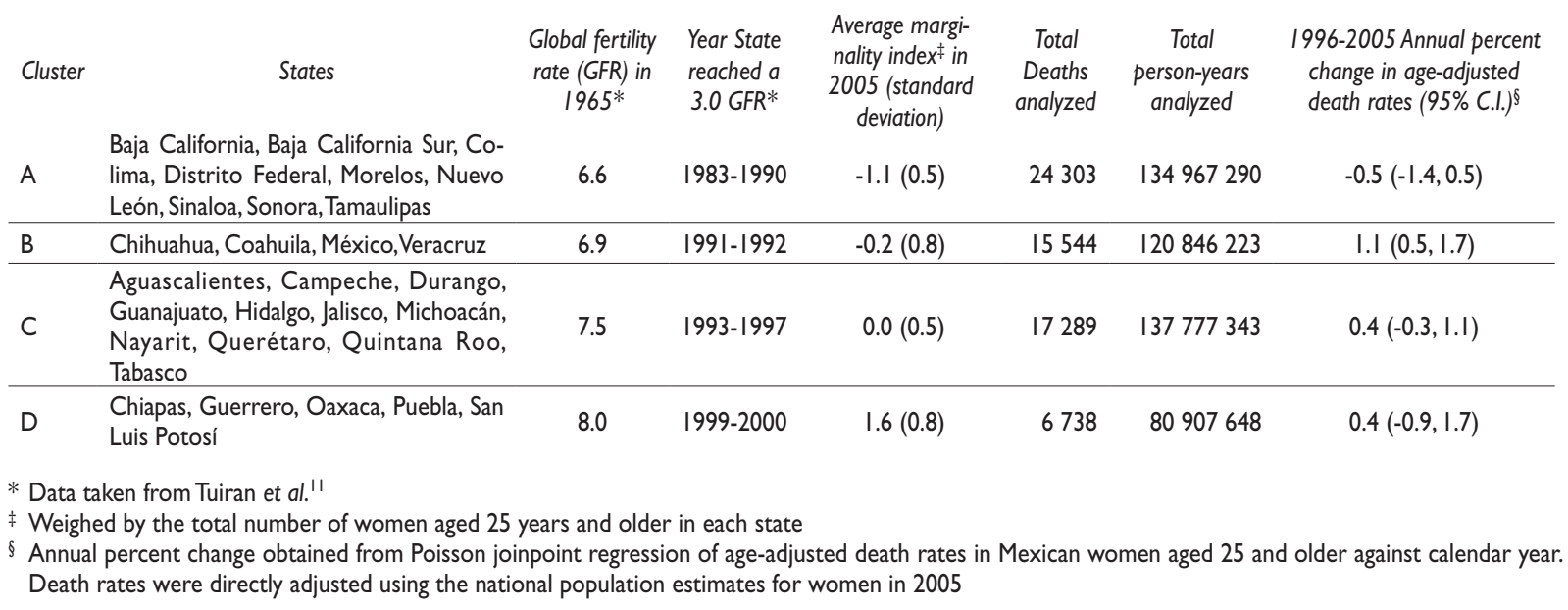

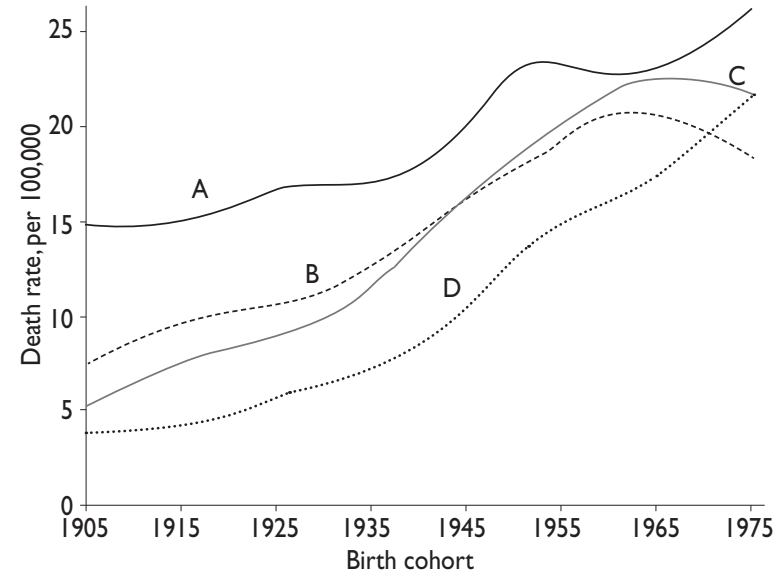

Figure 4. Age-Adjusted breast cancer death rates FOR BIRTH COHORTS IN FOUR FERTILITY REGIONS IN MEXICO. DEATH RATES ARE FOR WOMEN AGED 25 AND OLDER AND WERE derived from the fitted Holford Age-Period-Cohort MODEL. Death RATES WERE DiRECTLY ADJUSTED USING THE NATIONAL POPULATION ESTIMATES FOR WOMEN IN 2005

pronounced in cluster $\mathrm{D}$. If the population age structure is held constant at 2005 levels, women born after 1955 residing in different Mexican regions are expected to have breast cancer death rates between 18 and 26 per 100 000. In addition, breast cancer death rates for women more recently born in regions $\mathrm{B}$ and $\mathrm{C}$ have a lower mortality rate than women born in 1960 . However, because these cohorts contain fewer observations, 95\% confidence intervals for these rates overlap.

\section{Discussion}

Breast cancer death trends presented in this paper must initially be interpreted in terms of several potential artifactual explanations. First, mortality data might be affected by underreporting of deaths and by whether the death is certified or not by a physician, especially in poorly developed areas of Mexico during the first half of 1980s. During the 1990s and in more recent years, rising trends in breast cancer mortality could be explained to some extent by better diagnosis and reporting as more physicians and health care units became available in these areas. Second, ICD coding changes and population ageing can also artificially affect mortality trends. However, as mentioned in the methods section, no significant changes in ICD coding happened for breast cancer between the ninth and the tenth revisions of the ICD. Also, data shown here are either presented using age-adjusted or age-specific death rates. Therefore, neither ICD changes nor population ageing are likely explanations for the observed breast cancer mortality trends.

Secular trends in breast cancer mortality are the result of both survival and incidence changes. Over the past three decades, earlier disease detection through increased social awareness and mammographic screen- 
ing as well as the introduction of adjuvant endocrine therapy and more aggressive surgery have dramatically improved breast cancer survival. ${ }^{13}$ As a result, in many developed countries breast cancer mortality has been declining since the first half of the 1990s. ${ }^{14-19}$ This mortality decline is explained by both mammographic screening and treatment improvements. Thus, a rising breast cancer incidence ${ }^{20-22}$ with the progressive predominance of cases in earlier stages, as would be expected with effective screening, ${ }^{23,24}$ has been observed concomitantly with the reduction in breast cancer death rates. Also, the widespread use of adjuvant endocrine therapy at least partially explains the changing breast cancer mortality trend observed in the 1990s. ${ }^{25,26}$

Our results indicate that even when crude breast cancer death rates in women show an increasing trend in Mexico, the slope has progressively declined, especially since 1995. Additionally, since that year most age groups show a flattening breast cancer death rate trend, whereas death rates for women 75 and older continue to increase at $1.2 \%$ annually since the late $1980 \mathrm{~s}$. Our age-period-cohort analysis also shows a slight downward trend in death rates since 1995, indicating limited survival improvements in Mexico due to screening and adjuvant therapy. In fact, the five-year breast cancer survival in Mexico during the 1990 s was close to $60 \%,{ }^{27}$ a much lower figure than that observed in developed countries. $^{28}$

Despite the existence of official recommendations for breast self-examination and mammography since the early $1990 \mathrm{~s}^{29}{ }^{29}$ screening coverage has been very limited. Breast cancer cases continue to be detected by women in 90\% of instances and therefore they seek health care at an advanced stage, ${ }^{30}$ and a national survey conducted in 2006 indicates that only $16 \%$ of Mexican women had a breast cancer screening procedure. ${ }^{31}$

Although no specific data regarding adjuvant therapy use in Mexico exist, it likely was available for widespread use at roughly the same time than in developed countries. In the absence of effective screening strategies in the country and given a possibly rising breast cancer incidence, adjuvant therapy may be the main factor explaining the change in trends associated with calendar time observed in this analysis. The fact that we did not observe a reduction in death rates in mortality in any age group but only that rates stopped increasing in most of them suggests that the costs of adjuvant therapy have precluded its use in uninsured lower socioeconomic status Mexican women suffering from the disease. The Mexican health insurance program for the poor (seguro popular) has only recently incorporated breast cancer treatment in its coverage. ${ }^{32}$

Mexican women with breast cancer may benefit even more by adequately tailored screening programs and increased access to effective therapy. Such programs should be accompanied by adequate health education strategies to ensure that all Mexican women are aware of the benefits of mammographic screening and early breast cancer recognition and treatment. In developed countries, screening has been responsible for a 20 to $30 \%$ reduction in mortality and adjuvant therapy for an additional 5 to $10 \% .33-36$

Our age-period-cohort analysis also gives clues regarding breast cancer incidence trends. Incidence trends are captured in our analysis in the strong cohort effects detected. We found that breast cancer death rates have steadily increased in Mexican women born in the first three-quarters of the 20th century. Such increase was however higher for women born between 1940 and 1955 and lower afterwards.

Breast cancer etiology is complex and some risk factors may have differential effects in cases arising before and after menopause. In spite of this, epidemiologic studies in both types of cases have found several reproductive risk factors indicating greater exposure to endogenous hormones associated with breast cancer risk, especially estrogens but possibly also progesterone. These factors include early age at menarche, late age at menopause, late age at first full-term pregnancy and nulliparity. On the other hand, multiple full-term pregnancies, surgical removal of ovaries and breastfeeding are associated with a lower risk of developing breast cancer. ${ }^{37,38}$ In addition, use of both oral contraceptives and hormonal replacement therapy cause a small increase in breast-cancer risk. Obesity and alcohol consumption and certain mutations also increase breast cancer risk, whereas physical activity is probably protective. ${ }^{39}$

There is very limited information on trends in risk factors for breast cancer in Mexico and therefore we can only speculate on an explanation for the rising incidence trends in Mexico suggested by our analysis. We had, however, information on trends in fertility rates in Mexican states, an aggregate measure of reproductive breast cancer risk factors. As part of the demographic transition, fertility rates have dramatically fallen in Mexico, especially between 1974 and 1984, as a result of a birth control program including oral contraception, intra-uterine devices and surgery, ${ }^{10}$ but the fertility decline was faster in general in more developed Mexican states. In our analysis, we grouped the Mexican states into four clusters according to the speed of their fertility decline and identified trends by birth cohort. We found in all four state clusters strong cohort effects and a similar pattern with a period of faster increase in mortality associated with the cohort of birth, which occurred at earlier birth cohorts in regions with faster 
fertility declines and progressively at later birth cohorts in regions with slower fertility declines. Additionally, birth cohorts with very fast increases in mortality correspond to those likely to have benefited more from the birth control program in their reproductive ages. It seems unlikely that these trends can be explained only by improvements in death certification or access to health care that mainly occurred in region $\mathrm{D}$.

A cross-sectional relationship between fertility and breast cancer death rates in Mexico has been reported previously. ${ }^{40}$ In addition, a similar association between birth cohort mortality and fertility trends has been observed in Russia and Ukraine, ${ }^{41}$ whereas other analyses have linked fertility increases in women who bore children during the post-World War II period to breast cancer mortality reductions in developed countries. ${ }^{42}$

It is also conceivable that the rising mortality observed in the most recent birth cohorts in Mexico is the result, to some extent, of their greater exposure to nonreproductive breast risk factors such as obesity, western dietary patterns and alcohol consumption. In Latin America, substantial rapid changes are documented in patterns of foods and drinks that may reduce the risk of some dietary deficiencies but can also carry adverse shifts in the composition of diets, such the increasing energy intake from fats and oils an added sugar that are related with breast cancer risk with the concomitant increase in the incidence of obesity. In Mexico, the highest rates of breast cancer are observed in northern states along the Mexico-U.S. border where the Mexican diet has had a more rapid transition to a high energy U.S. diet. ${ }^{43}$

\section{References}

I. Knaul FM, Nigenda G, Lozano R,Arreola-Ornelas H, Langer A, Frenk J. Breast cancer in Mexico: a pressing priority. Reprod Health Matters 2008; I6(32): I |3-23.

2. Malvezzi M, Bosetti C, Chatenoud L, Rodriguez T, Levi F, Negri E, La Vecchia C. Trends in cancer mortality in Mexico, 1970-1999. Ann Oncol 2004; I5(II): I7I 2-8.

3. Althuis MD, Dozier JM,Anderson WF, Devesa SS, Brinton LA. Global trends in breast cancer incidence and mortality 1973-1997. Int J Epidemiol 2005;34(2):405-12.

4. World health Organization. ICD9 <-> ICD I0 translator. User's guide to electronic tables. Geneva:WHO, 1996.

5. Conapo.gob.mx [website]. México: Consejo Nacional de Población, (C2008 Available in: http://conapo.gob.mx/00cifras/5.htm [Consulted Aug 18 2008].

6. Fleiss JL, Levin B and Cho Paik M. Statistical methods for rates and proportions. 3rd. edition. New Jersey:Wiley, 2003.

7. Srab.cancer.gov [website]. Bethesda: National Cancer Institute; @ 2008 Available in: http://srab.cancer.gov/joinpoint/ [Updated Apr 15 2008; Consulted Sept 9 2008].

8. Kim HJ, Fay MP, Feuer EJ, Midthune DN. Permutation tests for joinpoint regression with applications to cancer rates. Stat Med. 2000;19(3):335-5I.
9. Holford TR. Age-Period-Cohort Analysis. In:Armitage P, Colton T. Encyclopedia of biostatistics. Second edition. London:Wiley, 2008. 10. Tuirán R, Partida V, Mojarro O y Zúñiga E. Tendencias y perspectivas de la fecundidad. Capítulo 3 [internet monograph]. Mexico: Conapo 2002. Available in: http://www.conapo.gob.mx/publicaciones/2002/03.pdf. II. Carstensen B.Age-period-cohort models for the Lexis diagram. Stat Med 2007;26(I5):3018-45.

12. R Development Core Team. R:A language and environment for statistical computing.Vienna: R Foundation for Statistical Computing, 2004. 13. Kobayashi S.What caused the decline in breast cancer mortality in the United Kingdom? Breast Cancer 2004; I I (2): I56-9.

14. Demers AA, Turner D, Mo D, Kliewer EV. Breast cancer trends in Manitoba: 40 years of follow-up. Chronic Dis Can. 2005;26(I):13-9. 15. Ruiz-Ramos M, Exposito Hernandez J.Tendencia de la mortalidad por cáncer en Andalucia entre 1975 y 2003. Med Clin (Barc). 2007; I 28(I2):448-52.

16. Louwman WJ, Voogd AC, van Dijck JA, Nieuwenhuijzen GA, Ribot J, Pruijt JF, Coebergh JW. On the rising trends of incidence and prognosis for breast cancer patients diagnosed 1975-2004: a long-term populationbased study in southeastern Netherlands. Cancer Causes Control 2008; I9(I):97-106. Epub Nov 242007.

17. Bosetti C, Bertuccio P, Levi F, Lucchini F, Negri E, La Vecchia C. Cancer mortality in the European Union, 1970-2003, with a joinpoint analysis. Ann Oncol 2008; I9(4):63I-40. Epub Feb I4 2008.

18. Hery C, Ferlay J, Boniol M,Autier P. Quantification of changes in breast cancer incidence and mortality since 1990 in 35 countries with

Caucasian-majority populations. Ann Oncol 2008; I9(6): I I87-94. Epub Mar 52008.

19. Westlake S, Cooper N. Cancer incidence and mortality: trends in the United Kingdom and constituent countries, 1993 to 2004. Health Stat Q 2008;(38):33-46.

20. Cleries R, Ribes J, Esteban L, Martinez JM, Borras JM. Time trends of breast cancer mortality in Spain during the period 1977-200I and Bayesian approach for projections during 2002-2016. Ann Oncol 2006; I7(I2): 1783-9I. Epub Sept I3 2006.

21. Ardanaz E, Moreno-Iribas C, Perez de Rada ME, Ezponda C, Floristan Y, Navaridas N, Martinez-Penuela JM, Puras A, Santamaria M, Ezpeleta I, Valerdi JJ, Pardo FJ, Monzon FJ, Lizarraga J, Ortigosa C, Resano J, Barricarte A. [Incidencia y mortalidad por cancer en Navarra, 1998-2002. Evolución en los ultimos 30 años]. An Sist Sanit Navar 2007;30(2):245-70.

22. Hery C, Ferlay J, Boniol M,Autier P. Changes in breast cancer incidence and mortality in middle-aged and elderly women in 28 countries with Caucasian majority populations. Ann Oncol 2008; 19(5): 1009-18. Epub Feb 212008.

23. Louwman WJ, van Diest PJ, van Beek MW, Schapers RF, NoltheniusPuylaert MB, Baak JP, Coebergh JW. Trends in breast cancer aggressiveness before the introduction of mass screening in southeastern Netherlands 1975-1989. Breast Cancer Res Treat 2002;73(3):199-206.

24. Holford TR, Cronin KA, Mariotto AB, Feuer EJ. Changing patterns in breast cancer incidence trends. J Natl Cancer Inst Monogr 2006;(36): 19-25. 25. Berube S, Provencher L, Robert J, Jacob S, Hebert-Croteau N, Lemieux J, Duchesne T, Brisson J. Quantitative exploration of possible reasons for the recent improvement in breast cancer survival. Breast Cancer Res Treat 2007;106(3):419-31.

26. Ernst MF, van de Poll-Franse LV, Roukema JA, Coebergh JW, van Gestel CM,Vreugdenhil G, Louwman MJ,Voogd AC. Trends in the prognosis of patients with primary metastatic breast cancer diagnosed between 1975 and 2002. Breast, 2007; I6(4):344-5I. Epub Feb I5 2007.

27. Flores-Luna L, Salazar-Martinez E, Duarte-Torres RM, Torres-Mejia G, Alonso-Ruiz P, Lazcano-Ponce E. Factores pronosticos relacionados con la supervivencia del cancer de mama. Salud Publica Mex. 2008;50(2):1 19-25. 28. Roohan PJ, Bickell NA, Baptiste MS, Therriault GD, Ferrara EP, Siu AL. Hospital volume differences and five-year survival from breast cancer.Am J Public Health. 1998;88(3):454-7. 
29. Robles SC, Galanis E. Breast cancer in Latin America and the Caribbean. Rev Panam Salud Publica. 2002; I I (3): 178-85.

30. Lopez-Carrillo L, Torres-Sanchez L, Lopez-Cervantes M, Rueda-Neria C. Identificación de lesiones mamarias malignas en México. Salud Publica Mex 200I;43(3):199-202.

31. Olaiz-Fernández G, Rivera-Dommarco J, Shamah-Levy T, Rojas R, Villalpando-Hernández S, Hernández-Avila M, Sepúlveda-Amor J. Encuesta Nacional de Salud y Nutrición 2006. Mexico: Instituto Nacional de Salud Pública, 2006.

32. Seguro-popular.salud.gob.mx [website]. México: Seguro popular. (c) 2008 [Updated July 19 2008; Consulted Oct 2 2008]. Available in: http://www.seguro-popular.salud.gob.mx/contenidos/menu_beneficios/ beneficios_gastos.html.

33. Lee $\mathrm{CH}$. Screening mammography: proven benefit, continued controversy. Radiol Clin North Am 2002;40(3):395-407.

34. Gorini G, Zappa M, Miccinesi G, Paci E, Costantini AS. Breast cancer mortality trends in two areas of the province of Florence, Italy, where screening programmes started in the 1970s and 1990s. Br J Cancer 2004;90(9): 1780-3.

35. Vervoort MM, Draisma G, Fracheboud J, van de Poll-Franse LV, de Koning $\mathrm{HJ}$. Trends in the usage of adjuvant systemic therapy for breast cancer in the Netherlands and its effect on mortality. Br J Cancer 2004 19;91(2):242-7.
36. Cox B. The effect of service screening on breast cancer mortality rates. Eur J Cancer Prev 2008; I7(4):306- I I.

37. Kelsey JL, Gammon MD, John EM. Reproductive factors and breast cancer. Epidemiol Rev 1993;I5(I):36-47.

38. Collaborative Group on Hormonal Factors in Breast Cancer. Breast cancer and breastfeeding: collaborative reanalysis of individual data from 47 epidemiological studies in 30 countries, including 50302 women with breast cancer and 96973 women without the disease. Lancet 2002;360(9328): 187-95.

39. Key TJ,Verkasalo PK, Banks E. Epidemiology of breast cancer. Lancet Oncol 200I;2(3): I33-40.

40. Lopez-Rios O, Lazcano-Ponce EC, Tovar-Guzman V, Hernandez-Avila M. La epidemia de cáncer de mama en México. Consecuencia de la transición demografica?. Salud Publica Mex 1997;39(4):259-65.

4I. Hirte L, Nolte E, Bain C, McKee M. Breast cancer mortality in Russia and Ukraine 1963-2002: an age-period-cohort analysis. Int J Epidemiol 2007;36(4):900-6.

42. Mettlin C. Global breast cancer mortality statistics. CA Cancer J Clin 1999;49(3): 138-44.

43. World Cancer Research Fund/American Institute for Cancer Research. Food, Nutrition, Physical Activity and the Prevention of Cancer: A global perspective. Washington: 2007. 